\title{
Air Quality and Meteorological Conditions Coupling Analysis of the Jingjinji District
}

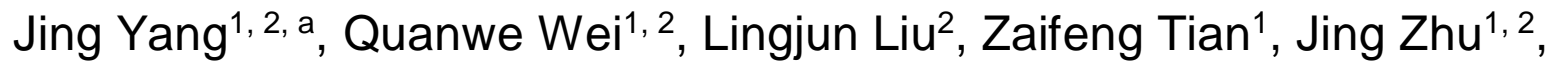 \\ Haibo Feng ${ }^{1}$
}

${ }^{1}$ Hebei Provincial Academy of Environment Sciences, Yaqing Road Shijiazhuang Hebei, China

${ }^{2}$ Hebei Zhengqi Environment Technology co., LTD, Yaqing Road Shijiazhuang Hebei, China

ajjphoenix@163.com

Keywords: Air Quality, Meteorological Condition, Jingjinji District.

\begin{abstract}
From different angles on the relationship between air pollution and meteorological elements preliminary studied, this research adopts the method of orthogonal analysis, by the analysis of day-to-day relationship between AQI (Air Pollution Index) and meteorological conditions of the Jingjinji District. Since April 2013 to June 2014, AQI of Jingjinji district had been being at Moderately Polluted level. Since October to March of the following year, there is a phenomenon of AQI peak. Heavy air pollution diffusion trend is basically originates from Shijiazhuang-Xingtai and Zhangjiakou-Xingtai, and the direction is SW-NE. The air flow conditions for have promoting effect to the contaminant spread, but not absolute. It is same to rainfall, AQI value at rainfall day will be smaller.
\end{abstract}

\section{Introduction}

Along with the integration of the Beijing-Tianjin-Hebei region (JingJinJi District), Jingjinji Dstrict would be growing integration together on politics, economy, culture, and environment. As the core of the Pan-Bohai Economic Circle, it is important position gradually. Deterioration of the ecological environment of the emerging issues such as sustainable development has been become the focus of international and domestic research and hot topics. With the speeding up of economic development and urbanization, there would be growing emissions of air pollutants [1,3], example as Particulate matter, Sulfur-Dioxide, Nitrogen Oxides, etc. Under the pollutions unceasingly and seriously expands, the main pollutants of atmosphere environment pollution problem is increasingly, such as the smog weather [7]. The air environmental pollution caused great harm to economic, development and human health, becoming a barrier to the sustainable development of JingJinJi District, worthy more and more attention $[6,9]$.

APEX (Asian Atmospheric Particle Environmental Change Studies) has an integrated the research on the atmospheric environmental problems by three main technical means (field observation, experimental research and numerical simulation) [2, 4]. With application of ground-based radar observations, aerial aerial and other advanced environmental detection technology [5, 8], it has an indepth and comprehensive research on near surface atmospheric particulate matter, ozone and other oxide, which has been achieved good results.

Based on limited air pollution monitoring site data of regional air pollution process and spatial distribution, the studies did not fully consider the effects of atmospheric pollution and pollution sources, meteorological conditions and many other factors. There are certain limitations just researching on the observational data virtue. Closely related to air pollution and meteorological conditions, meteorological elements tend to restrict the dilution and diffusion, transmission and transformation process of air pollutants, which affects the distribution of air pollutants and pollutant concentration. From different angles on the relationship between air pollution and meteorological elements preliminary studied, this research adopts the method of orthogonal analysis, by the analysis of day-to-day relationship between AQI (Air Pollution Index) and meteorological conditions of the Jingjinji District. 


\section{Method and database}

The city air quality real-time release system of China is an important part of national environmental air monitoring network. In 1998, the system has to achieve the key city air quality weekly report, which covering the whole country for the air quality daily in 2000. It has built more than 2000 automatic air monitoring station, initially formed air automatic monitoring network. CNEMC (China's National Environmental Monitoring Centre) is responsible for the system running, the key cities for the release and the point of $\mathrm{SO}_{2}, \mathrm{NO}_{2}$ and $\mathrm{PM}_{10}$ concentration data, updated every hour.

Jingjinji District covers two municipalities of five total, including China's capital, Beijing. There are 13 cities, such as Beijing (BJ), Tianjin (TJ), Shijiazhuang (SJZ), Qinhuangdao (QHD), Chengde (CD), Zhangjiakou (ZJK), Tangshan (TS), Langfang (LF), Baoding (BD), Cangzhou (CZ), Hengshui (HS), Xingtai (XT) and Handan (HD), possessed national environmental monitoring station and meteorological observing station.

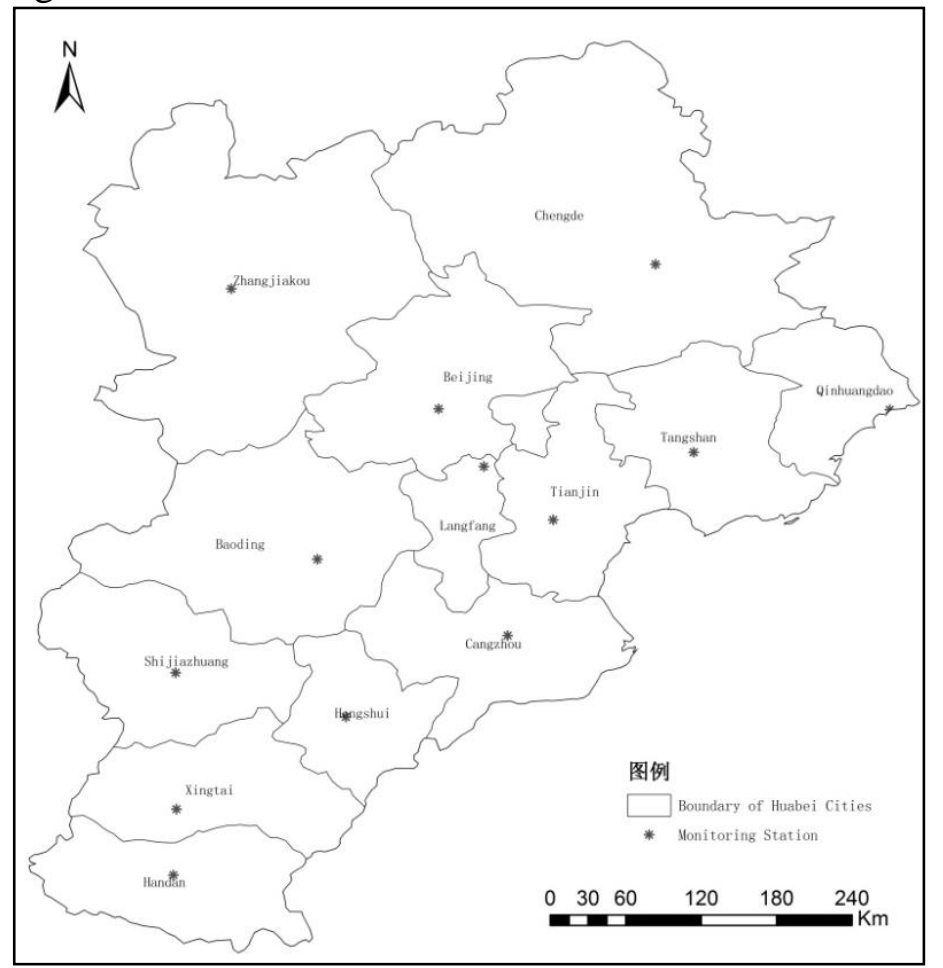

Fig 1 Jingjinji Distict and the monitoring Stations location

In this paper, there has collected the air quality data of the stations and the corresponding meteorological conditions since April 1, 2013 to June 30, 2014. The real-time air quality station data includes six classified indexes, such as $\mathrm{SO}_{2}, \mathrm{NO}_{2}, \mathrm{PM}_{10}, \mathrm{PM}_{2.5}, \mathrm{CO}$ and Ozone data, and the meteorological condition data are mainly wind speed, precipitation, wind direction, the maximum wind speed, static wind data, and so on.

Also there has collected the meteorological observing station data, which include 8 kinds of factors, such as precipitation, evaporation, maximum wind speed, maximum wind speed and direction, average speed, average wind speed and direction, average pressure, and average temperature. It has selected in ground climate days resource dataset V3.0 provided by the China Meteorological Data Sharing Service System.

\section{Results and Discussion}

\subsection{Calculating of AQI}

There is AQI (Air Pollution Index) of air quality, a representative of real-time air quality, calculated by $\mathrm{SO}_{2}, \mathrm{NO}_{2}, \mathrm{PM}_{10}, \mathrm{PM}_{2.5}, \mathrm{CO}$ and Ozone data. $\mathrm{AQI}$ is divided into six levels in accordance with the size of the air quality index, corresponding to the six categories of air quality. The index is the higher than the level, the more serious contamination explanation, for the greater harm to human health. Only characterizing the concentration degree of contamination, AQI index is not specific pollutants. 
Because 6 kinds of pollutant concentration limit AQI evaluation, there would be based on different target concentration limits converted into air quality sub-index AQI in the evaluation of the contaminant, according the corresponding pollutants concentration table on calculating AQI.

The Individual Air Quality Index $\left(I A Q I_{P}\right)$ has been evaluated by the formula.

$I A Q I_{P}=\frac{I A Q I_{H i}-I A Q I_{L O}}{B P_{H i}-B P_{L O}}\left(C_{P}-B P_{L O}\right)+I A Q I_{L O}$

AQI has been ranged from 0 to 500, which more than 100 defined as the standard exceed pollutants. Such as daily average $\mathrm{PM}_{2.5}$ concentration is $35 \mu \mathrm{m}$ which corresponding AQI value 50. The Air Quality Index (AQI) has been evaluated by the formula.

$A Q I=\max \left\{I A Q I_{1}, I A Q I_{2}, I A Q I_{3}, I A Q I_{4}, I A Q I_{5}, I A Q I_{n}\right\}$

Table 1 The corresponding table of concentration pollutions on calculating IAQI

\begin{tabular}{|c|c|c|c|c|c|c|}
\hline \multirow{2}{*}{ IAQI } & \multicolumn{6}{|c|}{ Pollutions Concentration $\left(\mu \mathrm{m} / \mathrm{m}^{3}\right)$} \\
\hline & $\mathrm{SO}_{2}$ & $\mathrm{NO}_{2}$ & PM2.5 & PM10 & $\mathrm{CO}$ & $\mathbf{O 3}$ \\
\hline 0 & 0 & 0 & 0 & 0 & 0 & 0 \\
\hline 50 & 50 & 40 & 35 & 50 & 2 & 100 \\
\hline 100 & 150 & 80 & 75 & 150 & 4 & 160 \\
\hline 150 & 475 & 180 & 115 & 250 & 14 & 215 \\
\hline 200 & 800 & 280 & 150 & 350 & 24 & 265 \\
\hline 300 & 1600 & 565 & 250 & 420 & 36 & 800 \\
\hline 400 & 2100 & 750 & 350 & 500 & 48 & $>800$ \\
\hline 500 & 2620 & 940 & 500 & 600 & 60 & $>800$ \\
\hline \multicolumn{7}{|c|}{ Table 2 The classification of air quality based on AQI value } \\
\hline \multicolumn{2}{|c|}{ Classification } & AQI & Air & evels & \multicolumn{2}{|c|}{ Color display } \\
\hline \multicolumn{2}{|l|}{$1^{\text {st }}$} & $0-50$ & \multicolumn{2}{|c|}{ Excellent } & \multicolumn{2}{|c|}{ Green } \\
\hline $2^{\text {nd }}$ & & $51-100$ & \multicolumn{2}{|c|}{ Good } & \multicolumn{2}{|c|}{ Yellow } \\
\hline $3^{\text {rd }}$ & & $101-150$ & \multicolumn{2}{|c|}{ Light Polluted } & \multicolumn{2}{|c|}{ Orange } \\
\hline $4^{\text {th }}$ & & $151-200$ & \multicolumn{2}{|c|}{ Moderately Polluted } & \multicolumn{2}{|c|}{ Red } \\
\hline $5^{\text {th }}$ & & $201-300$ & \multicolumn{2}{|c|}{ Severely Polluted } & \multicolumn{2}{|c|}{ Purple } \\
\hline $6^{\text {th }}$ & & $>300$ & \multicolumn{2}{|c|}{ Heavily Polluted } & \multicolumn{2}{|c|}{ Brown } \\
\hline
\end{tabular}

\subsection{Statistical analysis of AQI data}

Based on the AQI from April 2013 to June 2014, there could be found that the AQI of 13 cities are almost excessive standard of Excellent level. In general, the air quality in northern mountainous area of Jingjinji had been better than the mid-eastern plains, and the Moderately Polluted phenomenon almost had been appeared in February, slightly later than the mid-eastern plains.

Obviously, there is a seasonal rules of air pollution. Since October to March of the following year, there is a phenomenon of AQI peak, which the Maximum AQI value had been stabilizing above 300 such as Xingtai and Shijiazhuang. At the same time, there is a peak time also in June and October, but the valley time since April to May and August to September.

Specific to the local distribution, Shijiazhuang to Xingtai area is almost the entire AQI high value center, and low to Zhangjiakou to Chengde area. Heavy air pollution diffusion trend is basically originates from the above two centers, and the direction is SW-NE.

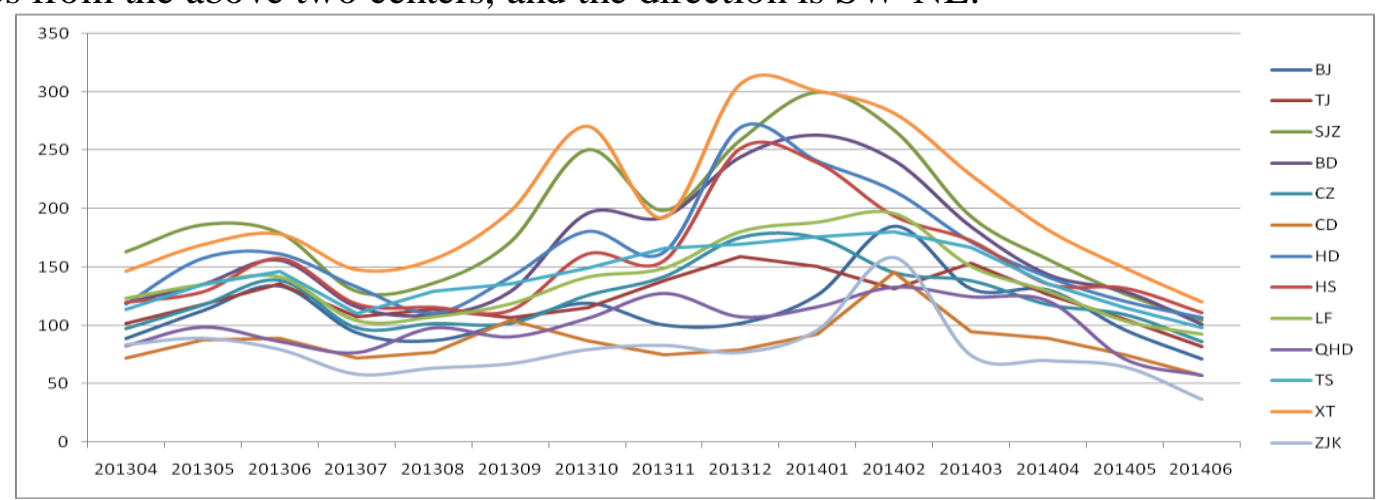

Fig. 2 The 13 cities AQI data of Jingjinji district since March 2013 to June 2014 


\subsection{Statistical analysis of meteorological data}

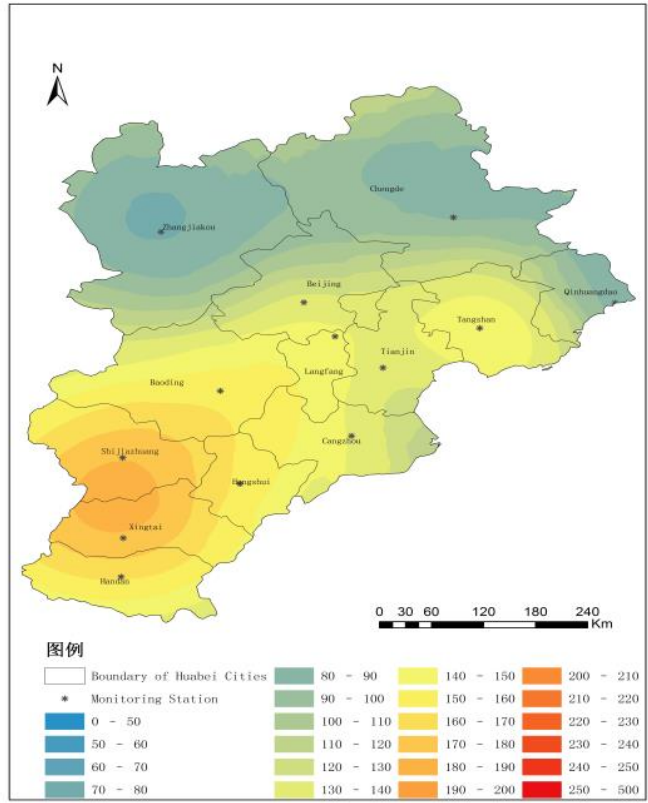

a. June 2013

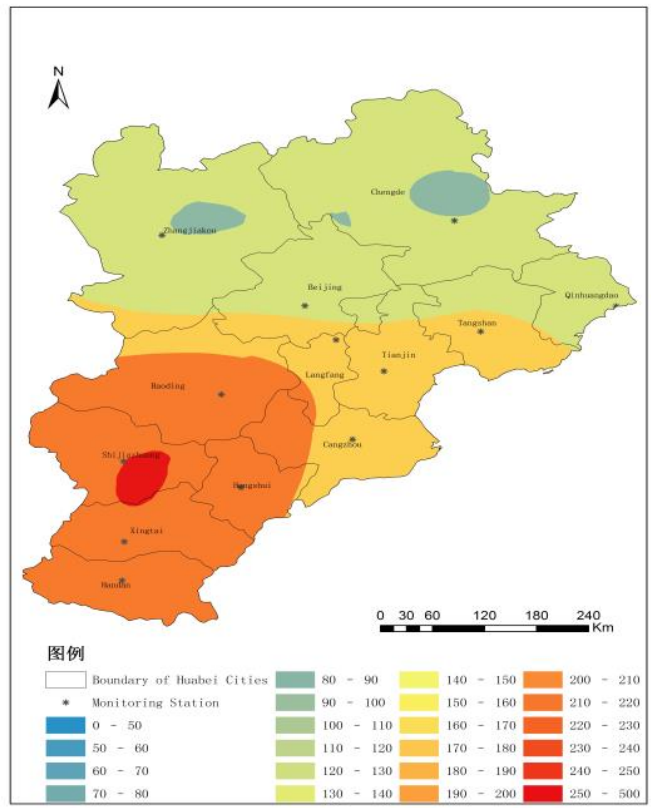

c. January 2014

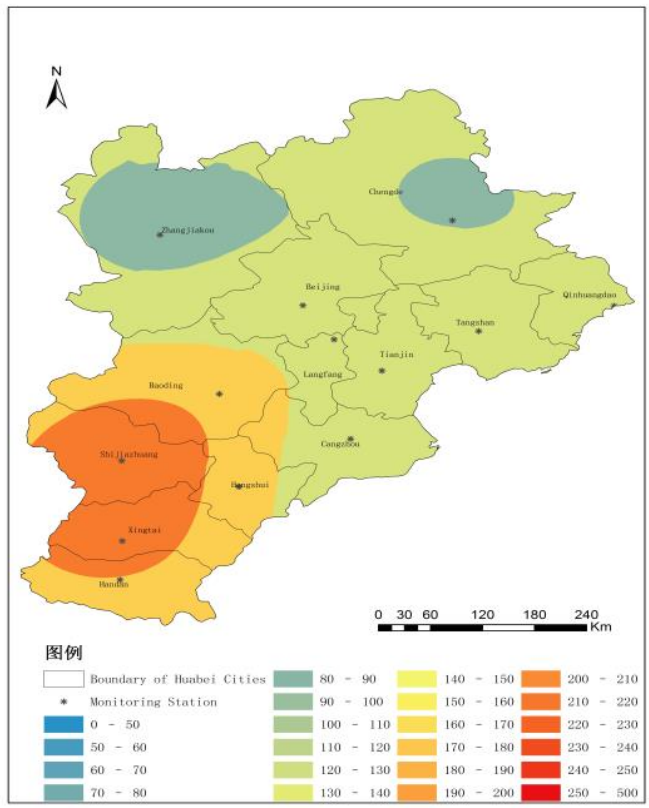

b. October 2013

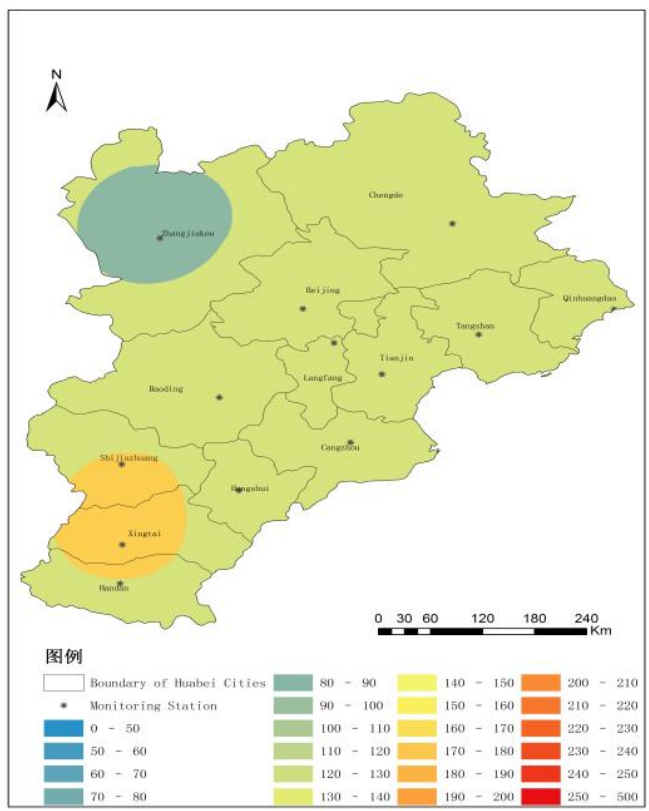

d. April 2014

Fig 3 The trend of AQI distribution of Jingjinji district and seasonal rules

There has collected the same period of 9 cities meteorological data for analysis, except Baoding, Langfang, Xingtai and Hengshui, without a site of monitoring. Basing the correlations analysis, there is same trend between the AQI and average wind velocity, but crosscurrent between the AQI and rainy day.

Table 3 The correlation analysis of AQI, average wind velocity and rain day

\begin{tabular}{ccccc}
\hline Correlation & day of $\mathbf{A Q I}>\mathbf{1 5 0}$ & day of $\mathbf{V}<\mathbf{3 0}$ & day of $\mathbf{V}<\mathbf{2 0}$ & rain day \\
\hline day of $\mathrm{AQI}>150$ & 1 & 0.447 & 0.297 & -0.458 \\
day of $\mathrm{V}<30$ & 0.447 & 1 & 0.896 & -0.528 \\
day of $\mathrm{V}<20$ & 0.297 & 0.896 & 1 & -0.321 \\
rain day & -0.458 & -0.528 & -0.321 & 1 \\
\hline
\end{tabular}

In comparison, the count of day which the average wind velocity is below $30 \mathrm{~m} / \mathrm{s}$ has stronger correlation with AQI. It is visible that the wind velocity has influence on AQI. The greater the wind 
is, the smaller the AQI. In other words, the air flow conditions for have promoting effect to the contaminant spread, but not absolute. It is same to rainfall, AQI value at rainfall day will be smaller.

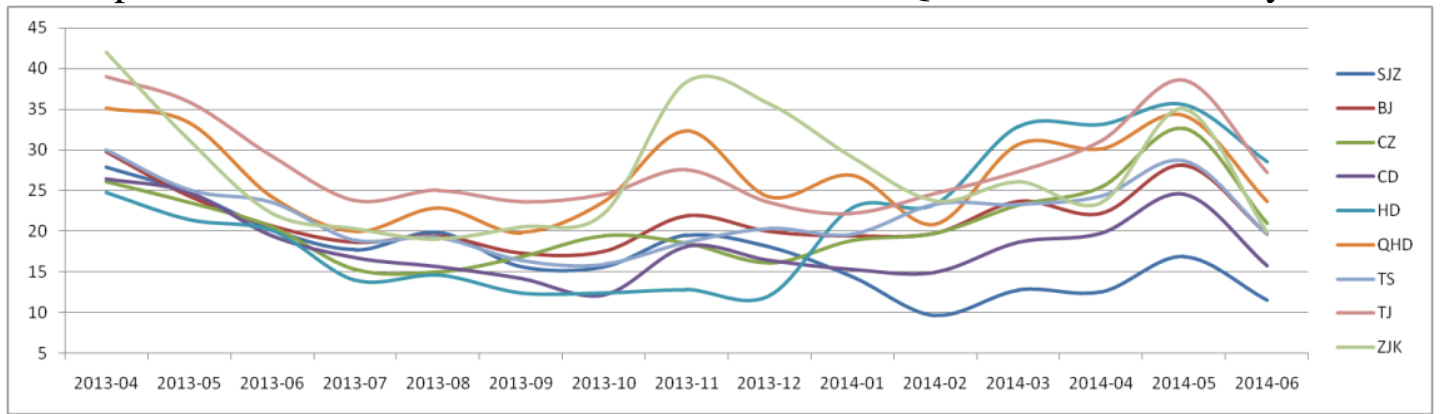

Fig. 4 The 9 cities average wind velocity of Jingjinji district since April 2013 to June 2014.

\subsection{Situation of air pollution in Jingjinji district}

Since April 2013 to June 2014, AQI of Jingjinji district had been being at Moderately Polluted level over 110 days. The heaviest pollution city had be Shijiazhuang, having 243 days at Moderately Polluted level and 61 days at Heavily Polluted level, almost $14 \%$ of the all year.

Since October to March of the following year, there is a phenomenon of AQI peak, which the Maximum AQI value had been stabilizing above 300 such as Xingtai and Shijiazhuang. At the same time, there is a peak time also in June and October, but the valley time since April to May and August to September. Heavy air pollution diffusion trend is basically originates from Shijiazhuang-Xingtai and Zhangjiakou-Xingtai, and the direction is SW-NE.

Basing the correlations analysis, there is same trend between the AQI and average wind velocity, but crosscurrent between the AQI and rain day. It is visible that the wind velocity has influence on AQI. The greater the wind is, the smaller the AQI. In other words, the air flow conditions for have promoting effect to the contaminant spread, but not absolute. It is same to rainfall, AQI value at rainfall day will be smaller.

\subsection{Factors of AQI}

The air quality of Winter in Jingjinji district is the worst, influenced by heating for the season, especially in Shijiazhuang and Xingtai. AQI at Spring and Autumn is on the high side affected by the fog, which against the pollutant diffusion.

Air pollution is affected by many factors, mainly including the meteorological conditions, pollution sources and intensity, topography and other natural factors and human factors, such as the urban traffic. The influence of meteorological conditions on the air pollution is most serious. The air flow conditions for have promoting effect to the contaminant spread, such as rainfall and wind.

Research on the relationship between air pollution and meteorological elements stays in appearance. It is needed to analyze its internal mechanism. In season and statistical data in this study has certain statistical significance, but the lack of physical mechanism support.

\section{References}

[1] Baumbach G, Baumann K, Graver A, et al. 1993. A tethersonde measuring system for detection of $\mathrm{O}_{3}, \mathrm{NO}_{2}$, hydrocarbon concentrations, and meteorological parameters in the lower planetary boundary layer. Meteor. Zeitsch rift, N.F., 2.

[2] Davis D D, Chen G, Chameides W, et al. 1993. A photo stationary state analysis of the $\mathrm{NO}_{2}-\mathrm{NO}$ system based on airborne observations from the subtropical tropical North and South Atlantic. Journal of Geophysical Research.

[3] Li Wenjie, Zhang Shihuang1, Gao Qingxian, et al. 2012. Relationship between Temporal-Spatial Distribution Pattern of Air Pollution Index and Meteorological Elements in Beijing, Tianjin and Shijiazhuang. Resources Science, Vol. 34, No. 8.

[4] MOK K M, HOI K I. 2005. Effects of meteorological conditions on $\mathrm{PM}_{10}$ concentrations: study in Macau. Environmental Monitoring and Assessment, Vol. 102(1-3).

[5] SHEN Jiafen, ZHANG Ling, MO Cehui, et al. 2006. Principal component and canonical correlation analysis for air pollutants and meteorological data in Guangzhou. Ecology and 
Environment. Vol. 15(5).

[6] Song Yanling, Zheng Shuihong, Liu Yanju, et al. 2005. Research on Characteristics of Air Pollution in Beijing. Journal of Applied Meteorological Science, Vol. 16, Suppl.

[7] STATHEROPOULOS M, VASSILIADIS N, PAPPAA. 1998. Principal component and canonical correlation analysis for examining air pollution and meteorological data. Atmospheric Environment, Vol. 32(6).

[8] Yang Guihua. 2010. Comprehensive Evaluation of Urban Air Pollution and Model Building. Dissertation for the Master Degree in Engineering.

[9] Zhou Jiangxing. 2005. Correlative Analysis on Relationship between Changes of Several Main Contaminations and Some Meteorological Elements. Journal of Applied Meteorological Science, Vol. 16, Suppl. 